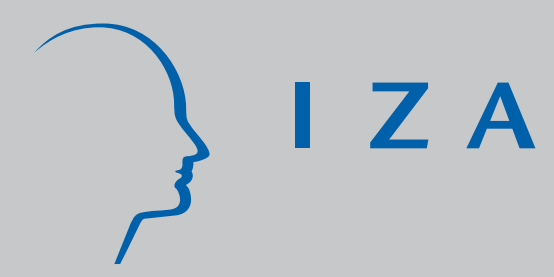

IZA DP No. 2446

Heterogeneous Human Capital and Migration:

Who Migrates from Mexico to the US?

Vincenzo Caponi

November 2006 


\title{
Heterogeneous Human Capital and Migration: Who Migrates from Mexico to the US?
}

\author{
Vincenzo Caponi \\ Ryerson University \\ and IZA Bonn
}

\section{Discussion Paper No. 2446 \\ November 2006}

\author{
IZA \\ P.O. Box 7240 \\ 53072 Bonn \\ Germany \\ Phone: +49-228-3894-0 \\ Fax: +49-228-3894-180 \\ E-mail: iza@iza.org
}

\begin{abstract}
Any opinions expressed here are those of the author(s) and not those of the institute. Research disseminated by IZA may include views on policy, but the institute itself takes no institutional policy positions.

The Institute for the Study of Labor (IZA) in Bonn is a local and virtual international research center and a place of communication between science, politics and business. IZA is an independent nonprofit company supported by Deutsche Post World Net. The center is associated with the University of Bonn and offers a stimulating research environment through its research networks, research support, and visitors and doctoral programs. IZA engages in (i) original and internationally competitive research in all fields of labor economics, (ii) development of policy concepts, and (iii) dissemination of research results and concepts to the interested public.
\end{abstract}

IZA Discussion Papers often represent preliminary work and are circulated to encourage discussion. Citation of such a paper should account for its provisional character. A revised version may be available directly from the author. 


\section{ABSTRACT \\ Heterogeneous Human Capital and Migration: Who Migrates from Mexico to the US?*}

In this paper I document the fact that the relationship between human capital, as measured by education, and migration choices among Mexicans is U-shaped: the highest and lowest educated tend to migrate more than the middle educated. I provide an explanation for the Ushaped relationship based on the interaction of two forces. On the one hand, there is a loss of human capital faced by emigrants, due to imperfect transferability, that is progressive with education and causes the negative relationship. On the other hand, the altruism towards future generations and the transmission of human capital from one generation to the next drives the positive relationship. I calibrate the model to match relevant moments from the Mexican and US Censuses, and use the calibrated model for policy evaluation. I evaluate the long run effect of the Progresa policy on education and migration. I show that, by giving a monetary contribution to poor families that send their children to school at lower grades, the Mexican government will improve the educational distribution of future generations and this in turn will shift the composition of immigrants towards the higher educated. Overall it will lower emigration from Mexico attenuating the pressure, especially of illegal immigrants.

JEL Classification: F22, J61, O15

Keywords: migration, Mexico, heterogeneous human capital, Progresa

Corresponding author:

Vincenzo Caponi

Department of Economics

Ryerson University

350 Victoria St.

Toronto, Ontario M5B 2K3

Canada

E-mail: vcaponi@ryerson.ca

\footnotetext{
* I wish to thank Audra Bowlus, Paul Klein and Lance Lochner, for all their support and useful suggestions. All errors remain mine.
} 


\section{Introduction}

By comparing data collected from the 2000 Mexican and US censuses, I show in this paper that the relationship between human capital, as measured by education, and migration choices among Mexicans is U-shaped: the highest and lowest educated tend to migrate more than the middle educated. ${ }^{1}$ Standard theories of self selection applied to migration fail to explain this puzzle. $^{2}$ The first objective of this paper is to provide an alternative model capable of explaining this particular characteristic of Mexican emigration. The second objective, given the particular relationship between migration and education, is to evaluate the long run implications of policies set to favor education in source countries or to control the quality and the volume of immigration flows. I look in particular at the Progresa program implemented by the Mexican government aimed at increasing the educational attainment of the Mexican population.

In order to understand what factors contribute to determining the relationship between education and migration I construct a theory that can explain the U-shaped emigration pattern. Building on Borjas (1993), I propose an application of the intergenerational altruistic model of migration. In the model the U-shape is generated by the interaction of two forces. On the one hand, there is a loss of human capital faced by emigrants, due to imperfect transferability, that is increasing with education. This results in a negative relationship between education and migration. On the other hand, altruism toward future generations and the transmission of human capital from one generation to the next results in a positive relationship. At lower levels of education the negative relationship dominates, while at higher levels dominates the positive. The result is the observed U-shape.

I consider human capital to be a country specific investment. Therefore, not all of the human capital accumulated in the source country can be used by immigrants to generate earnings in the destination country. I label the amount of human capital accumulated in the country of birth as intrinsic, and the amount used to generate earnings as marketable. The difference between the two represents the loss of human capital caused by imperfect transferability. By comparing the performance of Mexicans working in Mexico with those working in the US, I

\footnotetext{
${ }^{1}$ This fact is also documented by Chiquiar and Hanson (2005) (tables 2a nd 2b) They show that persons with zero years of formal education and with 13 to 15 years are more likely to migrate to the US than those with low, but positive, levels of schooling.

${ }^{2}$ See Borjas (1987) for an application of the Roy model to migration.
} 
find evidence that the return to education is higher for residents in Mexico than for immigrants in the US. This suggests that immigrants face a loss of human capital and that the loss is more than proportional to human capital. That is, very low skilled workers may have the same employment opportunities in the two countries, but higher skilled workers do not. Language and social barriers in the work environment, for instance, may prevent immigrants from using, in the destination country, all of the human capital accumulated in their native country. Thus, in my model I assume that immigrants face a loss of human capital when they move from the home to the destination country.

Human capital, however, is not only used to procure earnings, but is also an input in the production function of children's human capital. The distinction between intrinsic and marketable human capital is important to describe the process of intergenerational transmission of human capital. Although there is a consensus that the transmission of skills from parents to children is an important factor that contributes to the formation of children's human capital, a consensus about what exactly drives this transmission is not yet clear. If genetics is the major determinant, then the portion of human capital transmitted by this channel is not reduced by migration. Indeed, it is reasonable to believe that is the intrinsic human capital, rather than the marketable one, which is transmitted to future generations. Other channels though, could be affected by migration. Cultural traits, for example, may also be transmitted. Among them there could be traits responsible for the loss faced by immigrants, as with language. But the cultural channel of transmission is one that, differently from genetics, can be modified by parents. Parents can, to some extent, choose what to transmit to their children and avoid those traits that may constitute an obstacle for their assimilation. For these reasons I assume in my model that the intrinsic human capital enters the production function of children's human capital. That is, immigration does not diminish the ability of parents to transmit human capital to their children.

Given the above assumptions the model predicts, similarly to Borjas (1993), that if individuals are selfish then they are negatively selected in the destination country. Because at lower levels of education the loss of human capital is contained, and because in terms of utility the cost of migration is the same for all potential migrants, the individuals with lower levels of education have a higher incentive to migrate than those with higher levels of education. Conversely, if individuals only care about their offspring, then the model has the opposite prediction from Borjas (1993). In this case the loss of human capital is not important because it will be experi- 
enced only by the first generation. The benefit to second generation migrants of being born in the destination country is increasing in parents' education. This causes a positive relationship between human capital and emigration.

If individuals care both about themselves and their children, then at increasing levels of education, potential migrants face a trade off between their own decreasing current gain from migration, and the increasing future gain of their offspring. With the two forces at work the U-shaped emigration rate is, therefore, one possible outcome of the theory, in which at lower levels of education the first effect prevails and at higher levels, the second effect dominates the first one.

With respect to the policy experiments I perform, my findings are that the Mexican government policy by giving financial subsidies to poor families with children conditional on children's school attendance from grade third to ninth, will improve the educational attainment of future generations of Mexicans. ${ }^{3}$ This in turn will affect migration by increasing the quality and reducing the quantity of immigrants to the US. Conversely, a policy set to reduce the flow of migrants, by introducing a pecuniary cost to migration, would be effective in reducing migration flows. However, the reduction in migration would be more pronounced for the higher educated. This stems from the fact that the utility function is concave. At lower levels of education earnings and consumption are lower, such that an increase in earnings has a greater impact. This is why the incentive to migrate for the lower educated is higher, and, as long as there are no borrowing constraints, more difficult to reduce by restrictive policies. Overall, the effect of a restrictive migration policy is a worsening of the educational distribution of immigrants in the US, with no significant impact on the educational distribution in Mexico.

One contribution of my paper is to the literature on the selection mechanism of immigrants in a destination country. Borjas $(1987,2000)$ found that recent cohorts of immigrants in the US are negatively selected. Among them are Mexicans, which represent about $30 \%$ of the whole foreign born population in the US. Chiquiar and Hanson (2005), on the contrary suggest that Mexican immigrants are positively or intermediate selected. Using 1990 census micro data from both the US and Mexican censuses they found that, on average, Mexicans living and working in the US are more educated than Mexicans remaining in Mexico.

\footnotetext{
${ }^{3}$ This finding is consistent with the literature that recently evaluated the effect of Progresa in Mexico. See Behrman and Todd (2001) and Schultz (2004) for more details on the program and its evaluation.
} 
In this paper I follow the idea in Chiquiar and Hanson (2005) of evaluating the selection mechanism by comparing Mexican migrants with Mexican stayers. To do so I use the micro data from the US census and from the Mexican census collected in 2000. However, rather than limiting the comparison to the average of the educational attainment of the two groups I extend it to the entire educational distribution. In this way I show that the selection mechanism is more complex than hypothesized by Borjas $(1987,2000)$ or by Chiquiar and Hanson (2005). Indeed both selection mechanisms are at work at different levels of the human capital distribution, and this may also explain why there are conflicting results in the literature.

My explanation in terms of intergenerational altruism and transmission of human capital has also another important implication. Since Borjas (1993) does not distinguish between intrinsic and marketable human capital, he implicitly assumes that the loss of human capital faced by the first generation of immigrants is transmitted to the next generations. This, together with negative selection, leads to the conclusion that the assimilation of recent cohorts will be slower than the assimilation of past cohorts. My model, instead, suggests that future generations of recent immigrants from Mexico should be expected to assimilate as fast as descendants of previous cohorts. This is because selection at higher levels of human capital is positive and immigrants transmit more human capital to their children than that used by the labor market. Thus, second generation immigrants are expected to perform better than first generation immigrants, overcoming the disadvantage their parents faced in relation to the native population.

In the next section I briefly discuss the data and show the relevant evidence that motivates this paper. In Section 3, I introduce the theory and then, in Section 4 I discuss how the parametrization of the model is chosen the model. In Section 5, I evaluate alternative policy experiments. Section 6 concludes.

\section{Facts about the Mexican Migration}

Although the theoretical model I present in the next section aims at being general in explaining the reasons and consequences of migration for origin and destination countries, the empirical part of the model and the evidence I produce to support the model are taken from the Mexican migration experience. Mexico offers an unique opportunity for researchers to understand the causes of emigration, because the vast majority of Mexican migrants emigrate to the United 
States, where their performance in the labor market can be observed and compared with individuals remaining in Mexico.

The most recent Mexican census was designed to gather some information on the international migration experience of Mexicans. ${ }^{4}$ The questionnaire asked families to indicate if they had any relatives who emigrated abroad during the previous five years. If they did, they were asked to provide some basic information about those emigrants, including sex, age at the time of last emigration, location where the they had emigrated to, and their place of residence at the time of the census. The findings are not surprising: $97.05 \%$ of people reported as having migrated abroad between 1995 and 2000 had gone to the United States. The second country of destination was Canada with $0.6 \%$. The census also revealed that, in the timespan considered, some emigrants had returned to Mexico or left for some other country by the time of the census. The percentage of Mexican emigrants living in the U.S. in 2000 was only $76.64 \%$, while $16.69 \%$ were reported as having returned to Mexico.

The census does not cover the whole experience of Mexican migration. Since it was based on information provided by relatives, it could catch only emigrants who had left family members behind in Mexico. Emigrants who left with their whole (possibly extended) family are not included. Moreover, if we assume that migrants who left their families back home are more likely to return, then return migration is likely to be overestimated. Therefore, the conclusion we can safely draw from these figures is that the vast majority of Mexican emigrants emigrate to only one place: the US. This fact allows us to compare Mexican migrants with those who stayed in Mexico by simply comparing Mexicans in the US with those in Mexico.

To compare the educational attainment of emigrants and stayers I use data taken from the censuses of both Mexico and the US. ${ }^{5}$ The Mexican schooling system up to high school is divided into three levels of education. The first six years of schooling lead to an elementary degree. Three more years lead to a lower secondary degree. With another three years, students can obtain a high school degree. After high school there are various options, but the most common is for students to continue their education by attending university. Each of these levels grants a degree, and this is the main reason why the majority of the population has six, nine, or twelve

\footnotetext{
${ }^{4}$ The most recent Mexican Census is the: "XII Censo General de Poblacin y Vivienda, 2000" by the national institute of statistics (Itsituto National de Estadistica Geografia y Informatica INEGI), available at their web site.

${ }^{5}$ For the US I use the public-use microdata samples at 5\% (PUMS5) from the US Census Bureau. For Mexico I use the mentioned 2000 census.
} 
years of schooling or an university degree. A vast portion of the Mexican population is below the elementary school degree level having zero or only a few years of education (mostly three years). Table 2 shows the distribution of education in Mexico by sex. It clearly shows that the lowest level of education, which corresponds to zero years of education, and the highest, both high school and college, have a higher share among US immigrants than residents in Mexico. The large difference between immigrants and Mexican residents in the less than elementary group, could be the result of questions differently posed or interpreted in the US and Mexican censuses. For this reason in the remainder of the paper I group together the less than elementary and elementary school groups.

Table 1: Mexican Immigrants in the US compared with residents in Mexico

\begin{tabular}{lrrrr}
\hline & \multicolumn{2}{c}{ Men } & \multicolumn{2}{c}{ Women } \\
& Stayers & Migrants & Stayers & Migrants \\
\hline No School & 5.77 & 11.95 & 8.08 & 12.68 \\
Less Than Elementary & 17.18 & 7.58 & 17.92 & 8.12 \\
Elementary & 23.14 & 23.00 & 25.53 & 23.50 \\
Lower Secondary & 30.86 & 24.49 & 27.33 & 23.38 \\
High School & 13.38 & 22.24 & 14.47 & 21.54 \\
College & 9.68 & 10.73 & 6.67 & 10.77
\end{tabular}

Source: US Census, Public Use Micro Sample 5\%, 2000, Bureau of Census USA; XII Censo General de Poblacin y Vivienda, 2000, (Itsituto National de Estadistica Geografia y Informatica INEGI).

Table 2 shows that for both women and men the population of Mexican immigrants in the US is more disperse with respect to education than the population living in Mexico. In particular the zero schooling education group in the US is two times that in Mexico. This is also the case with the high school group. Table 2 clearly indicates that the emigration rate across educational groups is not flat, but follows a U-shape pattern.

Since the age structure of immigrants and Mexican residents is likely to be different, especially if we consider that in recent years, emigration from Mexico increased enormously and that immigrants are in large part young adults, it is useful to check if this pattern can be observed even within narrowly defined age groups. As we can see in Tables A.1 to A.3 in Appendix A this pattern recurs in all age groups. The immigration regression in Table 2 below reveals the U-shaped relationship between education and emigration when age is taken into account.

The interaction variables are intended to capture the differences across educational groups 
Table 2: Probability of Migration Conditional on Education

\begin{tabular}{llrr}
\hline & & Prob. of Migrating & Std. Error \\
\hline Education & No School & 0.2883 & 0.0036 \\
& Elementary & 0.0903 & 0.0010 \\
& Lower Secondary & 0.0569 & 0.0012 \\
& High School & 0.1510 & 0.0017 \\
& College & 0.1224 & 0.0026 \\
\hline Age $\times$ & No School & -0.0047 & 0.0001 \\
& Elementary & -0.0003 & 0.0000 \\
& Lower Secondary & 0.0012 & 0.0001 \\
& High School & 0.0008 & 0.0001 \\
College. & -0.0008 & 0.0001 \\
\hline N. of Obs & 365315 & \\
R. Sq & 0.1161 &
\end{tabular}

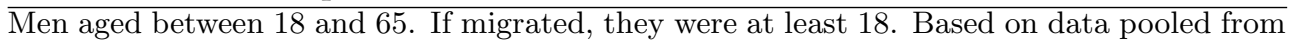
the two censuses. The table reports the linear probability Regression where the independent variable is a dummy variable that takes value one if the observation comes from a Mexican in the US and zero if from a Mexican in Mexico. The dependent variables are dummies for each level of education along with interaction variables for age and educational groups. The age variable is effective age minus 25 .

and/or age groups. By running a regression of the immigration dummy on all independent variables, I obtain the probability that a person of a given age, born in Mexico emigrated to the US. Figure 1 reports the coefficients on the dummies for educational attaintment. The reference age group in the regression is $25,{ }^{6}$ which is the average age of migrants. The points in the graph represent the probability that a person of this group immigrated to the US, conditional on the level of education. Clearly having zero years of formal education or a high school and college degree increases the probability of migration. This does not appear to be the case with respect to an elementary or lower secondary degree. Further, college education decreases the probability of migrating, although it is still higher with respect to the middle educated. This fact is not entirely surprising, if students who self-select into university are also likely to be those that already have high expectations about their future in Mexico. We also must take into account that the skills acquired at this level of education may be, at least for some disciplines, highly specific to the country. ${ }^{7}$

\footnotetext{
${ }^{6}$ The age variable reported in the regression is in fact the real age minus 25 , so that persons aged 25 have a value of zero for this variable.

${ }^{7}$ Law, political science, literature, to some extent medicine and other disciplines are chosen with a clear intent to remain in Mexico.
} 
Figure 1: Emigration Rate by Educational Group

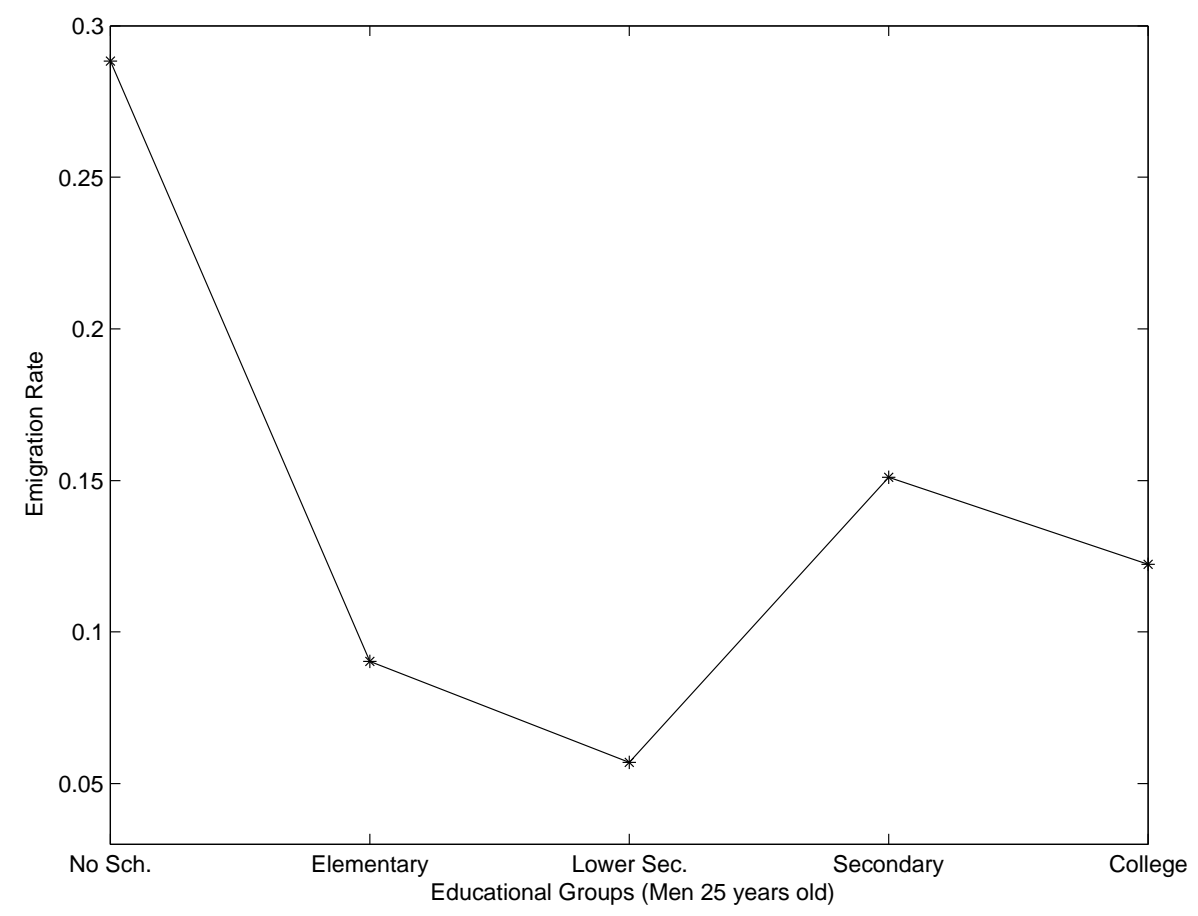

Another piece of evidence to add to this puzzling pattern of emigration is the returns to education of Mexicans residents in Mexico compared to Mexicans who emigrated to the US. Table 3 shows the regression of log hourly earnings on years of schooling, experience, experience squared, a dummy that indicates if the person is an immigrant in the US, an interaction variable of this dummy and years of schooling, and finally the experience accumulated in the US market by immigrants given by age minus age at migration. The sample consists of males aged between 18 to 65 , who migrated at the age of at least 18 if an immigrant, in full time work over a year, where full time is at least 30 hours per week and less than 100. College graduates were excluded from the regression. ${ }^{8}$

The intercept in the regression measures the log wage for a man with zero education working in Mexico. The coefficient on the immigrant dummy measures the difference between the log

\footnotetext{
${ }^{8}$ As we have seen the choice of college may be motivated by different factors than the choice of other levels of education, and the interaction of this choice with migration is likely to have a different explanation than the one I provide. To better understand this interaction it would be useful to characterize more in details the choice of college education including the field studied. However the focus of this paper is to understand the choice of migration at lower levels of education. Later I discuss briefly the consequences in terms of the loss of generality of this choice.
} 
Table 3: Returns to Education - Mexicans Immigrants Compared to Non-migrants

\begin{tabular}{lrr}
\hline & Coeff. & Std. Err. \\
\hline Intercept & -0.3787 & 0.0126 \\
Immigrant Dummy & 1.8003 & 0.0258 \\
Yrs of School & 0.0899 & 0.0009 \\
Yrs of School times Imm. Dummy & -0.0528 & 0.0021 \\
Experience & 0.0248 & 0.0008 \\
Experience ${ }^{2} / 100$ & -0.0259 & 0.0015 \\
Exp. in US & 0.0150 & 0.0022 \\
Exp. in US $/ 100$ & -0.0191 & 0.0055 \\
\hline N. of Obs & 153207 & \\
R. Sq & 0.2378 & \\
\hline
\end{tabular}

wage in Mexico and the log wage in the US at zero years of education. If we assume that earnings are given by a wage rate common for every person working in the same country multiplied by human capital, and that at zero years of schooling there is no loss of human capital, then this difference measures the wage gap between Mexico and the US. Table 3 indicates that the wage in Mexico is about $17 \%$ that in the US. The coefficient on years of schooling measures the Mincerian return to education in Mexico, while the coefficient on the interaction between the immigrant dummy and education measures the difference between the returns to schooling of a Mexican working in Mexico and a Mexican working in the US. We can see that this coefficient is negative and significant, suggesting that every extra year of schooling is worth $5.28 \%$ less for those working in the US than for those working in Mexico. As education is acquired in Mexico by both immigrants and stayers, we can interpret those lower returns as a loss of human capital due to imperfect transferability. It is further evident that this loss is more than proportional to the level of human capital. ${ }^{9}$

In the next section I will build on these facts to construct a theoretical model that is capable of explaining the U-shape pattern of emigration. The next section introduces the model.

\footnotetext{
${ }^{9}$ The regression suggests that the loss of human capital is in fact exponential. However, since I do not test for alternative specifications, the exponential functional form remains only one possible among others. In any case, the fact that the coefficient is negative and significant, as opposed to zero, does imply that the loss is more than proportional and not linear in education.
} 


\section{The Model Economy}

The model economy analyzed below consists of two countries that are characterized by different total factor productivity, education distributions, and human capital production functions. In each country in any given period three generations of agents are alive. The oldest generation is retired and enjoys the fruits of the previous period of work, in the form of their savings. Adults, representing the middle generation, work and raise their children. The youngest generation consists of children, whose only role is acquiring the level of education decided by their parents. Working generates earnings that are proportional to the human capital possessed by an individual, and to the wage rate paid by firms which depends on the country where the individual works. Earnings are used to buy the consumption good, pay for the education of children and saved for the next period of life. Education is acquired from teachers. It is assumed that teachers have at least the same level of education that children are acquiring. In this economy only children acquire education, while adults are the only ones that make decisions. They decide the education for their children, the level of savings and, if born in the origin country, whether to remain there or to migrate to the destination country. Only migration from the origin to the destination country is considered, because the economy is such that for any level of education earnings generated in the destination country by the native population are higher than those in the origin country.

\subsection{Value of Being Born in the Destination Country}

Because adult agents born in the destination country do not need to decide about migration, their problem is simpler and is analyzed first. Using a recursive representation the value of being an adult having been born in the destination country is

$$
V_{d}\left(h_{t}\right)=\max _{\left\{s_{t}, x_{t}\right\}}\left\{\log \left(c_{t}-a\right)+\beta\left[\log \left(c_{t+1}-\gamma a\right)+\theta E V_{d}\left(h_{t+1}\right)\right]\right\},
$$

subject to

$$
\begin{aligned}
& c_{t}+w_{d, t} \tau\left(e^{\delta s_{t}}-1\right)+x_{t}=w_{d, t} h_{t} \\
& c_{t+1}=R_{t+1} x_{t},
\end{aligned}
$$


while the human capital, in the destination country, is accumulated according to the following function

$$
\log \left(h_{t+1}\right)=\eta_{d} s_{t}+\kappa \log \left(h_{t}\right)+\epsilon_{t+1},
$$

with

$$
\epsilon_{t+1} \sim N\left(\mu_{\epsilon}, \sigma_{\epsilon}^{2}\right)
$$

The utility directly derived from consumption by the adult generation in the current period $t$ and in the next period $t+1$ is represented by $\log \left(c_{t}-a\right)+\beta \log \left(c_{t+1}-\gamma a\right)$, while $E V_{d}\left(h_{t+1}\right)$ is the expected value for the future generations. This value is indexed by $d$ for destination country, and is multiplied by $\theta \in[0,+\infty)$ which represents the degree of altruism of parents toward their children. The amount of education given to children is indicated by $s_{t}$. The cost of education, in terms of efficiency units involved in the process, is given by $\tau\left[\operatorname{Exp}\left(\delta s_{t}\right)-1\right]$. It reflects the fact that higher levels of education cost more, since the returns to education of teachers are convex in education. Multiplying the efficiency cost by the wage rate $w_{d, t}$ in the destination country, I obtain the monetary cost parents pay for their children's education. Savings are represented by $x_{t}$, and $R_{t+1}$ is the interest paid on those savings. The parameter $\beta$ discounts future consumption. There is also a minimum requirement of consumption $a$ that indicates the subsistence level. This is assumed to be higher in adulthood than in old age, when it is discounted by $\gamma \in(0,1)$. This is primarily because adults need to provide for their children, while elderly people only for themselves. Human capital, in the destination country, is accumulated according to the following function

$$
\log \left(h_{t+1}\right)=\eta_{d} s_{t}+\kappa \log \left(h_{t}\right)+\epsilon_{t+1},
$$

with

$$
\epsilon_{t+1} \sim N\left(\mu_{\epsilon}, \sigma_{\epsilon}^{2}\right)
$$

The parameter $\eta_{d}$ corresponds to the returns to education which are allowed to be country specific. Education is more efficiently translated into human capital if the human capital of parents is higher, reflecting the intergenerational transmission of ability. The uncertainty of 
the returns to the education investment is reflected by the shock $\epsilon$, which is identically and independently distributed.

\subsection{Value of Moving}

The adult agent born in the origin country can choose to migrate $\left(\psi_{t}=1\right)$ or stay $\left(\psi_{t}=0\right)$, where $\psi$ is a dichotomous variable that indicates the migration choice. Conditional on migrating, we have the following problem

$$
V\left(h_{t}, \xi \mid \psi_{t}=1\right)=\max _{\left\{s_{t}, x_{t}\right.}\left\{\log \left(c_{t}-a\right)-\xi+\beta\left[\log \left(c_{t+1}-\gamma a\right)+\theta E V_{d}\left(h_{t+1}\right)\right]\right\},
$$

where $\xi$ is a stochastic disutility factor, distributed as

$$
\xi \sim \log N\left(\mu_{\xi}, \sigma_{\xi}^{2}\right)
$$

The budget constraint is

$$
c_{t}+w_{d, t} \tau\left(e^{\delta s_{t}}-1\right)+x_{t}=w_{d, t} h_{t}^{(1-\zeta)},
$$

where $\zeta \in(0,1)$ represents the loss of human capital. The next generation's human capital is accumulated by the same function as in equation 4 .

The budget constraint reflects the fact that part of the human capital is lost through the transfer and this loss is increasing with the level of human capital. Notice that the value for the next generation is typically different from the value of migrating. This is because the children of migrants are considered natives and, therefore, are not subject to any utility cost of being in the destination country.

\subsection{Value of Staying}

The problem of the agent who decides to stay is more complicated. In this case the expected value of the future generation takes into account the possibility of children choosing to migrate in adulthood. The recursive form of the problem is synthesized by the following

$$
\begin{aligned}
& V\left(h_{t} \mid \psi=0\right)=\max _{\left\{s_{t}, x_{t}\right\}}\left\{\log \left(c_{t}-a\right)+\beta \log \left(c_{t+1}-\gamma a\right)+\right. \\
& \left.\beta \theta\left\{\int_{\hat{\xi}}^{\infty} E V\left(h_{t+1} \mid \psi_{t+1}=0\right) d F_{\xi}(r)+\int_{0}^{\hat{\xi}} E V\left(h_{t+1} \mid \psi_{t+1}=1\right) d F_{\xi}(r)\right\}\right\},
\end{aligned}
$$


where $F_{\xi}(r)$ is the density function of the shock $\xi$ and $\hat{\xi}=V\left(h_{t+1} \mid \psi_{t+1}=1\right)-V\left(h_{t+1} \mid \psi_{t+1}=0\right)$ subject to

$$
c_{t}+w_{o, t} \tau\left(e^{\delta s_{t}}-1\right)+x_{t}=w_{o, t} h_{t}
$$

and

$$
\log h_{t+1}=\eta_{o} s_{t}+\kappa \log h_{t}+\epsilon_{t+1}
$$

The parameter reflecting the returns to education here is indexed by $o$, to indicate that the human capital is accumulated using the technology available in the source country. It is finally possible to characterize the migration decision, together with other decisions, as follows

$$
V\left(h_{t}, \xi\right)=\max _{\left\{s_{t}, x_{t}, \psi_{t}\right\}}\left\{\left(1-\psi_{t}\right) E V\left(h_{t}, \xi \mid \psi_{t}=0\right)+\psi_{t}\left(E V\left(h_{t}, \xi \mid \psi_{t}=1\right)\right)\right\}
$$

\subsection{Population Flows and Distribution Changes in the Origin Country}

The solution to the problem in 7 is characterized by three optimal policy functions for the choice of savings, education and migration: $x\left(h_{t}, \xi\right), s\left(h_{t}, \xi\right)$ and $\psi\left(h_{t}, \xi\right)$. Once the policy functions are calculated, given an initial distribution of human capital in the origin country, it is possible to compute the population flow out of the country and the change in the human capital distribution. The emigration rate depends on the distribution of the psychic cost as well as that of human capital. The distribution of the psychic cost is the same for everyone. Therefore, conditional on human capital, the probability that one person migrates calculated before knowing the realization of the shock is equal to the share of individuals who will migrate after the shock is known. The following

$$
e\left(h_{t}\right)=\operatorname{Prob}\left\{\psi\left(h_{t}, \xi\right)=1 \mid h_{t}\right\}=\operatorname{Prob}\left\{\xi \leq V\left(h_{t}, \xi \mid \psi_{t}=1\right)-V\left(h_{t}, \xi \mid \psi_{t}=0\right)\right\},
$$

represents the emigration rate, i.e. the proportion of agents who decide to migrate at any level of human capital. The population of adults staying in the origin country after the decision to emigrate is

$$
P_{t}^{r}=P_{t} \int_{0}^{\infty}[1-e(h)] d F_{t}(h)
$$


where $P_{t}^{r}$ is the population of adults who decide to stay, $P_{t}$ is the population size before the emigration decision and $d F\left(h_{t}\right)$ the distribution of human capital before the migration decision.

Following emigration, the distribution of human capital changes, and the new one is

$$
F_{t}^{r}(h)=\frac{P_{t}}{P_{t}^{r}} \int_{0}^{h}[1-e(y)] d F_{t}(y) .
$$

The human capital of next period adults is a function of their parents human capital as well as acquired education, the latter being also a function of parents human capital. Therefore

$$
F_{t+1}(h)=\frac{P_{t}^{r}}{P_{t+1}} \int_{0}^{\infty} I\left(h_{t+1}(y) \leq h\right) d F_{t}^{r}(y),
$$

where $I(\cdot)$ is the indicator function, shows the next period human capital distribution of adults, where

$$
\log h_{t+1}\left(h_{t}\right)=\eta_{o} s_{t}\left(h_{t}\right)+\kappa \log h_{t}
$$

The labor force, the total amount of labor devoted to the production of the consumption good, is composed of only adult agents. However, not all adults participate in the labor force. Some adults educate the next generation and are not included in the labor force as defined above. The production of consumption good follows the production function

$$
Y_{j, t}=A_{j} K_{j, t}^{\alpha} L_{j, t}^{1-\alpha}
$$

where $K_{t}$ is aggregate capital and $L_{t}$ is the aggregate labor supply in terms of efficiency units, $A>0$ and $\alpha \in(0,1)$. Firms maximize profits.

The aggregate labor supply for the consumption goods sector at time $t$ is given by the following

$$
L_{t}=P_{t}^{r}\left\{\int_{0}^{\infty} h(y) d F_{t}(y)-\int_{0}^{\infty} s(y) \tau\left(e^{\delta s(y)}-1\right) d F_{t}(y)\right\} .
$$

The first integral gives the aggregate number of efficiency units available in the economy, while the second term specifies the amount of those units employed in the education sector.

Given the savings decisions of agents present in each country at any point in time, the total amount of savings can also be calculated as 


$$
S_{j, t+1}=P_{j, t}^{r} \int_{0}^{\infty} x(y) d F_{j}^{r}(y) .
$$

However, the total amount of physical capital in each country also depends on the assumptions made about international capital markets. Here, I assume that the the country is small relative to the world market and that capital is free to move across international borders. In this scenario, the interest rate is determined in the world market and it is set as given. Consequently, physical capital is either exported or imported, so as to keep the interest rate at the fixed international level. Therefore

$$
R^{w}=R_{j}=A_{j} \alpha K_{j}^{\alpha-1} L_{j}^{1-\alpha}=A_{j} \alpha k_{j}^{\alpha-1}
$$

where $R^{w}$ is the world interest rate and $k=\frac{K}{L}$ is the physical capital per efficiency unit of labor. Because $R^{w}$ and, consequently, $R_{j}$ are constant, $k_{j}$ is also constant. This implies that there will be a flow in or out of savings to compensate any change in $L_{j}$. I can characterize the net investments abroad as follows

$$
N I_{j, t}=S_{j, t}-K_{j, t+1}
$$

Another implication of having a free international capital market is that wages are also constant, since the marginal product of labor is constant. This implies that

$$
A_{o} k_{o, t}^{\alpha-1}=A_{d} k_{d, t}^{\alpha-1},
$$

or

$$
\frac{A_{o}}{A_{d}}=\left(\frac{k_{d, t}}{k_{o, t}}\right)^{\alpha-1}
$$

where wages are given by

$$
w_{j, t}=(1-\alpha) A_{j} k_{j, t}^{\alpha} .
$$

Therefore we can express the ratio of wages in the origin and destination countries in terms of the TFPs 


$$
\frac{w_{o}}{w_{d}}=\frac{A_{o}}{A_{d}}\left(\frac{k_{o, t}}{k_{d, t}}\right)^{\alpha}=\frac{A_{o}}{A_{d}}\left(\frac{A_{o}}{A_{d}}\right)^{\frac{\alpha}{1-\alpha}}=\left(\frac{A_{o}}{A_{d}}\right)^{\frac{1}{1-\alpha}} .
$$

\subsection{Equilibrium}

The equilibrium in the origin country economy is defined as follows. Given an initial distribution of education $F_{0}\left(h_{0}\right)$, initial quantities of physical capital $K_{0}$ and population $P_{0}$, a recursive competitive equilibrium is given by a set of policy functions for savings $x\left(h_{t}, \xi\right)$, education $s\left(h_{t} x i\right)$, and migration $\psi\left(h_{t}, \xi\right)$, value functions as in equation 7 , aggregate prices $\left\{R_{t+1}, w_{j, t}\right\}$, law of motions for aggregate physical capital $K_{t}$ and population, and a distribution of human capital $F_{j, t}$, such that:

- given an international equilibrium in the physical capital market, the level of capital present in the country is such that its marginal product equals the world interest rate;

- the wage rate equals the marginal product of labor;

- given the interest rate and the wage rate the policy functions satisfy the value functions subject to the individual constraints;

- given complete depreciation of physical capital, total investments are equal to the domestic amount of capital plus net investments exports;

- finally, the total amount of labor, in terms of efficiency units, evolves following equation 13.

\section{Estimation Procedure}

In order to evaluate the model most of the parameter estimates are chosen by matching relevant moments from the data using the concept of "indirect inference". Exceptions are made for the parameter $\beta$, which, being the period length years long is set equal to $0.9907^{120}$ (i.e., 0.99 per quarter). The implied interest rate is equal to $4 \%$ per year. Consequently, I set $R=3.2434$.

Because the model provides an explanation of migration decisions for Mexicans that acquire levels of schooling below college, I consider only education decisions up to a maximum of 15 
years. $^{10}$

Also the subsistence levels of consumption $(a)$ are chosen to reflect the extreme poverty line for expenditure given by the World Bank for Mexico. In August 2000, the amount reported in US dollars at purchasing parity power, averaging rural and urban areas, was 85.05 dollars per month. I calculate this amount to be about $30 \%$ of the life time earnings of the lowest educated group of Mexicans living in Mexico. I set $\gamma=.5$ to reflect the fact that during elderly agents do not have to provide for their children.

\subsection{Matching Data Moments}

All of the other parameters of the model are deduced by matching a set of simulated moments to the selected moments from the observed data. The regression in Table 3 reports biased estimates of the return to education, the wage gap between immigrants and non-immigrants, and the loss of human capital due to imperfect transferability. The bias is induced in the data, because the amount of human capital possessed by individuals is not observed, but only the years of schooling are. To obtain unbiased estimates of the parameters, I use the notion of "indirect inference" (Gourieroux and Monfort (1996)). The method consists in reproducing the same biased regression calculated with the observed data with simulated data obtained from the model. The same biased estimators can be obtained by omitting the variable that is unobservable in the data from the simulated regression. This way unbiased estimates can be obtained by choosing the parameters of the model that minimize the distance between the estimates obtained from the data and the simulated ones. To implement the procedure, the first step, given a set of parameters, is to solve the model. Then, I simulate a set of $T \times N$ individuals populating the economy, characterized by $T$ pairs of random values for the shock distributions $\epsilon$ and $\xi$ and $N$ possible values for the discretized state variable of parents' human capital. Therefore, I evaluate the migration decisions of all individuals, as well as the earnings and the education acquired in the previous period, and build a dummy variable that takes the value of one if the individual migrates, and zero otherwise. Using the simulated data I run

\footnotetext{
${ }^{10}$ The main effect of the constraint is that it does not allow children of more educated parents to acquire more education than the first generation had. However, we could speculate that in Mexico most college educated children come from parents that are also college educated, while the options available to children of less than college educated parents are mostly lower than college education. This is, in part, confirmed by the presence in Mexico of a wide variety of programs that last less than 4 years and are offered to high school graduates to acquire technical skills as an alternative to college.
} 
an auxiliary regression with log earnings as the dependent variable, education, the immigrant dummy variable and the interaction between the two as independent variables. This process is then repeated $S$ times, and the coefficients of the regressions averaged out. Because the human capital of individuals in the regression is omitted, the coefficients obtained by the auxiliary regression are affected by the same bias as the ones in Table 3 .

Similarly, from the simulated data I compute several moments that have a counterpart in the observed data. These include the emigration rates and the educational distribution for the four educational groups considered, the mean and variance of the education distribution in the US, and the mean of log earnings distributions in the US.

Finally, I choose the parameters of the model so that the biased coefficients of the auxiliary regressions and the simulated moments are as close as possible to their counterparts.

Table 4 shows the values assigned to all parameters, while Table 5 shows the moments chosen to be matched. The last column of table 4 contains the values of the parameters set using statics from other sources or normalized. The rest of the table shows the parameters obtained by the estimation procedure. The last three rows contain those parameters that are allowed to vary across the countries.

\begin{tabular}{|c|c|c|c|c|}
\hline & \multicolumn{2}{|c|}{ Calibrated } & \multicolumn{2}{|c|}{ Fixed } \\
\hline$\theta$ & 2.9 & & $\bar{\beta}$ & 0.3083 \\
\hline$\kappa$ & 0.5 & & $a$ & 0.0476 \\
\hline$\zeta$ & 0.5 & & $\gamma$ & 0.5000 \\
\hline$\tau$ & 0.8 & & $w_{u s}$ & 1.0000 \\
\hline$\delta$ & 0.0 & & $\mu_{\epsilon}$ & 0.0000 \\
\hline$w_{m x}$ & 0.1 & & & \\
\hline$\sigma_{\epsilon}$ & 0.1 & & & \\
\hline$\mu_{\xi}$ & 3.4 & & & \\
\hline$\sigma_{\xi}$ & 0.0 & & & \\
\hline & Mexico & US & & \\
\hline$\eta_{j}$ & 0.0310 & 0.0404 & & \\
\hline$\mu_{h j}$ & 0.8076 & 1.1935 & & \\
\hline$\sigma_{h j}$ & 0.7346 & 0.4458 & & \\
\hline
\end{tabular}


Table 5: Data and Simulated Moments

\begin{tabular}{llrr}
\hline & & Simulation & Data \\
\hline Emigration Rates & No School & 0.2827 & 0.2853 \\
& Elementary & 0.0889 & 0.0877 \\
& Lower Secondary & 0.0570 & 0.0578 \\
& High School & 0.1527 & 0.1513 \\
\hline Education distrib in MX & No School & 0.0624 & 0.0639 \\
& Elementary & 0.4568 & 0.4464 \\
& Lower Secondary & 0.3317 & 0.3616 \\
& High School & 0.1491 & 0.1481 \\
\hline Education distrib in US & Average & 13.4536 & 12.8600 \\
& Variance & 3.5416 & 3.5380 \\
& Average H.C. in US & 1.2107 & 1.2680 \\
\hline Auxiliary Regression & & \\
\hline Immigrant Dummy & & 1.8024 & 1.8003 \\
Return to Education $\left(\eta_{\text {mx }}+\right.$ bias $)$ & 0.0925 & 0.0899 \\
Return to Education $\left(\eta_{\text {us }}+\right.$ bias $)$ & 0.1154 & 0.1002 \\
Loss Human Capital $(\zeta+$ bias $)$ & -0.0518 & -0.0528 \\
\hline
\end{tabular}

\subsection{Results}

The parameters that indicate the returns to human capital are smaller than the biased parameters obtained in the OLS regressions. Thus, the bias in both countries is positive. This is because the relationship between the unobserved human capital of parents and schooling is positive, as is the relationship between earnings and the unobservable. For both the US and Mexico, the OLS estimates do not include individuals with a college degree or higher, therefore it is not surprising that the estimates of the return to education are low.

A feature of the model is that at lower levels of schooling it predicts that emigrants are negatively selected on the unobservable, while at higher levels the selection is positive. The probability of migrating is a function of human capital. Given the U-shaped relationship between human capital and migration, at low levels of schooling the probability of migration decreases with human capital. In this tract of the curve those with lower human capital conditional on education tend to migrate more, hence the negative selection. This is why the (log of the) calibrated Mexican wage rate is lower than the difference between US and Mexican wages reported in Table 3. At higher levels of schooling, the relationship between migration and human capital is positive. In this tract of the curve those with higher human capital conditional on 
education tend to migrate more, hence the positive selection. The total effect is a combination of the two. The fact that the parameter indicating the loss of human capital is greater than the one implied by the OLS regression $\left(\zeta=\frac{.0528}{.0899}=.5873\right)$ signifies that overall Mexican migrants are positively selected in the US. The positive selection of the higher educated compensates for the negative selection of the lower educated.

Given the great loss in human capital, the model also predicts that there is a very strong bond between generations. Both altruism and intergenerational transfers are high. The parameter $\kappa$, which measures the intergenerational transfer of human capital from parents to children, is calibrated at about $50 \%$. That is half of the human capital accumulated by parents is transmitted to their children. The parameter $\theta$ measures the altruism of parents toward their children. The value of 2.95 means that adults care more about their offspring than about themselves when looking at the future.

\section{Education and Immigration Policies}

The next step is to evaluate migration and education policies using the calibrated model. I propose two simulation experiments. In the first part of this section I answer the following question: what are the effects on both education and emigration of the Progresa program, a policy implemented by the Mexican government to improve educational standards of the Mexican population?. As there is a strong and peculiar relationship between education and migration, this policy should be expected to have an effect not only on educational attainment but also on migration decisions.

The second part of the section looks at policies implemented in the destination country that have the objective of reducing the immigration flow. Those policies act so as to lower the incentive to migrate. Once again the effects of such policies are not only on the migration flows but also on the educational distribution of immigrants, as well as the educational distribution of the population remaining in the source country. Although I look at two policy options that are implemented by different sovereign governments, and may therefore not be easily interchangeable, knowing what effects they have may assist the US and Mexican governments in negotiating agreements that have the objective of managing the mass migration phenomenon from Mexico to the US. 


\subsection{The Progresa Program}

The Progresa program was started in Mexico in 1997. ${ }^{11}$ The program, which aims to increase school attendance of children from poor families in rural areas, consists of conditional monetary contributions to poor families with school age children who prove that they attend grades third to ninth at an educational establishment. The contributions increase with the grade, reflecting the higher opportunity cost of education at higher grades. To evaluate the program in the context of the model, I calculate how the schedule of contributions translates in a reduction of the cost of schooling as parameterized in the model.

Table 6 shows the contribution schedule to poor families that have school children attending school. The first column indicates the monthly payments in current pesos (these values are taken from Schultz (2004)), the second column the yearly contributions (12 times the monthly transfer) in PPP adjusted US dollars in 2000. However, in the model the educational choice is continuous. I therefore interpolate the points in the schedule and calculate a linear "discount" function in education. Then I apply the discount to each level of education and recalculate the parameters of the education cost function that reflect the discounted cost of education.

Table 6: Transfer Schedule for the Progresa Program

\begin{tabular}{|c|c|c|c|c|c|}
\hline Grade & Mo. $(\text { pesos })^{a}$ & $\operatorname{Yr}(\mathrm{USD} 2000)^{b}$ & Cum. ${ }^{c}$ & Share LT Inc. ${ }^{d}$ & Model $^{e}$ \\
\hline Third & 70.00 & 169.35 & 169.35 & 0.0028 & 0.0047 \\
\hline Fourth & 80.00 & 193.55 & 362.90 & 0.0059 & 0.0067 \\
\hline Fifth & 105.00 & 254.03 & 616.94 & 0.0100 & 0.0092 \\
\hline Sixth & 135.00 & 326.61 & 943.55 & 0.0154 & 0.0120 \\
\hline Seventh & 200.00 & 483.87 & 1427.42 & 0.0232 & 0.0152 \\
\hline Eighth & 210.00 & 508.06 & 1935.48 & 0.0315 & 0.0189 \\
\hline Ninth & 225.00 & 544.35 & 2479.84 & 0.0404 & 0.0232 \\
\hline
\end{tabular}

Notes: $a$ Monthly figures in pesos 1998, source Schultz (2004); $b$ derived yearly figures from $(a)$ converted in ppp adjusted 2000 US dollars; $c$ implied cumulative subsidies assuming that a child attend up to the corresponded grade; $d$ implied percentage of the subsidy out of the life time income of a parent with zero education (the life time income is calculated following regression in table 3 ); $e$ same as point $d$ but based on the new parametrization of the model.

The new parameters are then applied to individuals with lower levels of human capital, who are considered to be poor, while the old parameters are applied to the rest of the population.

\footnotetext{
${ }^{11}$ For more information about the program see Schultz (2004). The program has also other provisions that are aimed at reducing poverty and malnutrition in general. However, I will consider only the part of the program that is concerned with education.
} 
Figure 5.1 shows how the educational distribution in Mexico changes due to the effect of the Progresa policy.

Figure 2: Educational Distribution in Mexico Before and After the Progresa Program

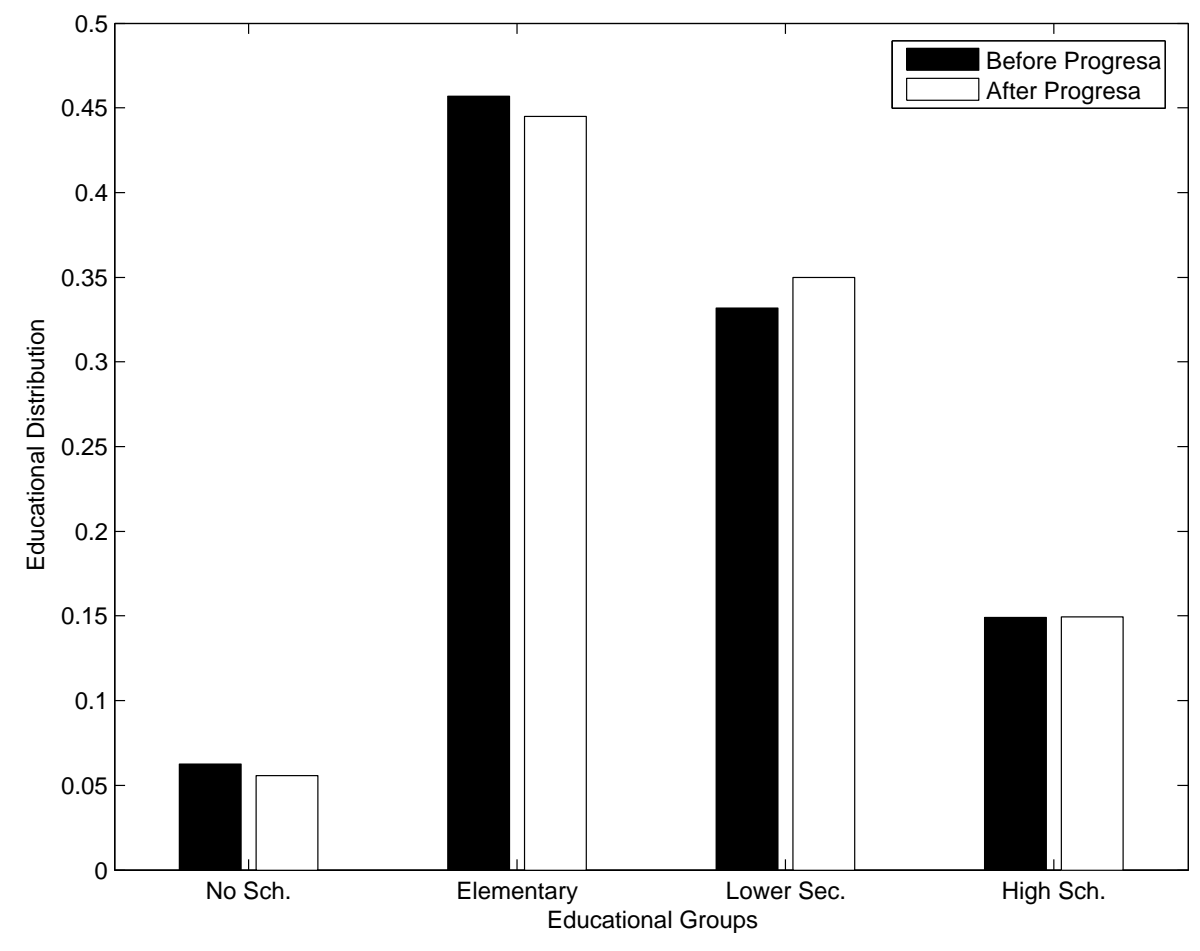

It shows that educational attainment improves by reducing the share of no schooling and increasing that of lower secondary, up to ninth grade. Not surprisingly, the effect of the program stops at the ninth grade, since this is where the transfers terminate. Because school is now cheaper, poor families acquire more education for their children. However, marginal children add less human capital to the pool of educated with the same grade, because their parent's human capital is lower. This is demonstrated in Figure 3, where the emigration rates before and after the Progresa program are represented. At lower levels of education, immigrants are negatively selected. Therefore, having lower human capital at any given level of education, results in higher emigration rates. At higher levels of education, the selection is positive. This is why lower levels of human capital after the program lead to lower emigration rates.

Overall, the shift of educational distribution causes a decrease in the emigration rate. This 
Figure 3: Emigration Rates Before and After the Progresa Program

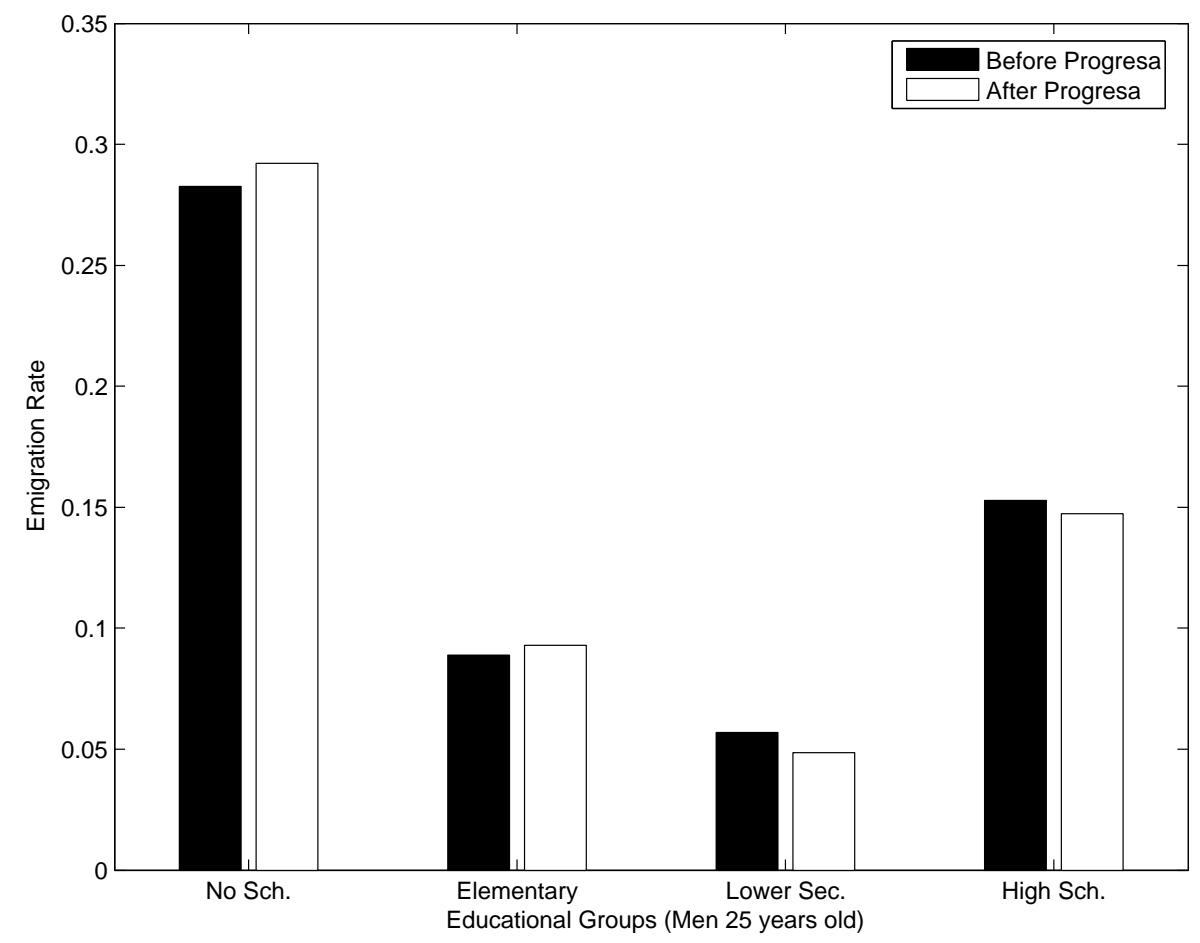

is shown in Table 7. The first and the third columns show the numbers of immigrants (in thousands) in the US by educational groups. All groups, except elementary, send less immigrants.

Table 7: Mexican Immigrants in the US Before and After the Progresa Program

\begin{tabular}{|l|r|r|r|r|r|r|r|r|r|}
\hline & \multicolumn{4}{|c|}{ Before the Program } & \multicolumn{3}{c|}{ After the Program } & \\
\hline & Stayers & Imm. & Rate & Perc. & Stayers & Imm. & Rate & Perc. & Change \\
\hline No School & 1652 & 651 & 28.27 & 21.19 & 1475 & 609 & 29.22 & 20.50 & -6.49 \\
Elementary & 12092 & 1180 & 8.89 & 38.41 & 11782 & 1205 & 9.28 & 40.59 & 2.13 \\
Low Sec. & 8780 & 531 & 5.70 & 17.27 & 9257 & 472 & 4.85 & 15.88 & -11.15 \\
High School & 3946 & 711 & 15.27 & 23.14 & 3956 & 684 & 14.74 & 23.04 & -3.78 \\
Total & 26470 & 3073 & 10.40 & 100.00 & 26470 & 2970 & 10.09 & 100.00 & -0.39 \\
\hline
\end{tabular}

The no-schooling group sends less immigrants simply because the pool of potential migrants with no schooling is smaller. In fact, the third and the seventh columns of Table 7 show that the emigration rate among them is higher after the Progresa program, reflecting the lower human capital possessed, conditional on education. However, the share of persons with the lowest level 
of education before migration decreases proportionally more than the increase in the emigration rate. The total effect is a decrease in the number of immigrants. The elementary educated group of persons is more numerous after the program, and although the emigration rate for this group is slightly lower, the total effect is an increase in the number of emigrants sent to the US. Also in this group persons have lower human capital conditional on education after the program. However, differently from the previous group, selectivity in immigration works in both ways, negative and positive. At lower levels of human capital the selectivity is negative, but at higher levels within the group it is positive. The total effect depends on the relative strength of each.

The secondary educational group increases after the program. However, for this group the selection is positive. Therefore, given that like in other groups persons have lower human capital conditional on education, the number of emigrants is lower. There is also another effect that reduces the emigration rate caused by the reduction in the cost of education. Since the cost is now lower, the value of staying in the origin country is higher. Therefore, the incentive to migrate is lower. This effect can be seen in the high school group. They have the same level of human capital conditional on education before and after the program. Therefore, the change in their behavior is not dictated by a change in unobservable human capital. However, because of the stochastic shocks to education investment, some of the high school educated end up being poor. For them the Progresa program is relevant since they will take advantage of the contributions offered. That is why some of them prefer to remain in the origin country after the program is in place.

Overall, the number of emigrants to the US falls as a result of the program. The reduction is from about 3.07 million to 2.97 million persons. This corresponds to a change of about $3 \%$ which is concentrated at the lowest and higher educational levels.

\subsection{Restrictive Immigration Policy}

Turning to destination country policies, I now examine what happens if the destination country implements restrictive policies to control the flow of immigrants. I assume that such policies can be evaluated by introducing monetary cost of moving. The choice of the monetary cost is also helpful to characterize policies as discriminating among immigrants, favoring the more educated against the lower educated ones. The US, differently from other countries like Canada and New 
Zealand, do not have a policy that strongly discriminates immigrants on grounds of education. ${ }^{12}$ Most of the immigrants that legally enter the US are sponsored by a relative American citizen. A smaller part of them is sponsored by an employer. However, the total number of all immigrants is kept to a maximum of 675,000 per year (though this number in some years can be higher). Because there are many more applications every year than the number of visas the government plans to issue, applicants may have to wait to become permanent resident.

However, many immigrants in the US, especially from Mexico, choose to immigrate illegally. Hanson and Spilimbergo (1999) report estimates suggesting that illegal immigrants crossing the border that divides Mexico from the US are as much as 160,000 per year - a number that matches the one of legal immigrants from Mexico. Moreover, according to Hanson and Spilimbergo (1999), the effort put in patrolling the US-Mexican border has little effect on reducing illegal immigration. Another policy aimed at discouraging illegal immigration is to impose fines on employers who hire them. The rationale of this policy is to reduce the gain from illegal immigration, as employers willing to hire illegal immigrants would pay them less to insure themselves against the risk of being mulcted.

In the following experiment I look at the consequences of a decision by the US to introduce stricter laws against employment of illegal immigrants. I assume that the effect of stricter laws would be similar to a fee immigrants would have to pay to enter the US. Although the fee is a great simplification, it does reflect several features of this type of policy. First of all, as most of the illegal immigrants belong to the lower end of the educational distribution, it is reasonable to assume that the cost of such a policy would affect more lower educated migrants than higher educated ones. Given that the gain from migration is proportional to education, subtracting the same amount of money from every immigrant leads to a higher cost in terms of gain reduction from migration for the lower educated than for the higher educated.

However, higher educated immigrants are also affected. A tighter policy against illegal immigrants would increase the number of applications for legal immigration making the queue for everybody longer. Thus, the cost is applied to everyone.

Urrutia (1998) finds that an entry fee applied to every immigrant would be effective in

\footnotetext{
${ }^{12}$ Canada, for example, admits every year a large number of immigrants compared to its population $(0.65 \%$ compared to the $0.35 \%$ of the US). Most of these immigrants are admitted through a point based system. Points are gained by applicants for permanent residence on the basis of several characteristics, education being one of the most important.
} 
selecting immigrants with more human capital, and would maximize the welfare gain resulting from migration in the destination country. Figure 4 shows the emigration rates from Mexico before and after the introduction of a monetary cost of migration. I assume this cost to be .05 i.e. the cost is about $5 \%$ of life time earnings of the individual with the lowest level of education. ${ }^{13}$ The figure clearly shows that the policy is effective in reducing immigration. Table 8 illustrates the reduction in the flows of immigrants by educational groups.

Figure 4: Emigration Rates Before and After the Restrictive Policy

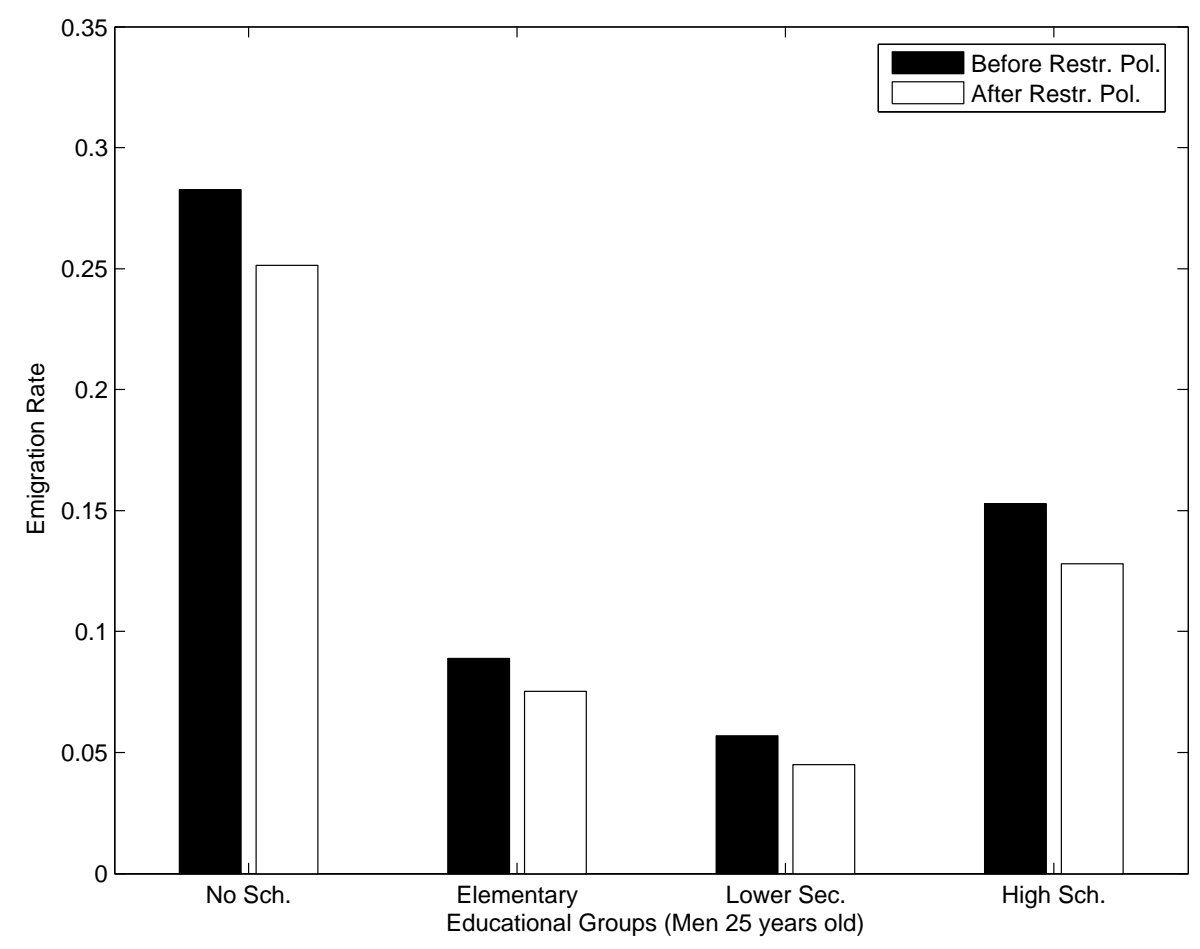

Looking at the last column, it is interesting to note that even if in principle the policy is discriminatory, it impacts more on higher educated persons than on lower educated. This is explained by the fact that potential immigrants compare the utility of remaining in their home country with the utility of migrating. Because the utility function is concave, increases in earnings and consumption have a stronger effect at low levels of human capital than at higher levels. At the lowest levels of human capital, for example, consumption in the origin country

\footnotetext{
${ }^{13}$ Notice that this cost is about $30 \%$ of the life time earnings of the same individual working in Mexico. However, I assume that there no borrowing constraints to finance migration. Therefore even if the cost must be paid up front before leaving Mexico, it can be paid with earnings earned in the US.
} 
is close to the subsistence level, this means that the utility is close to minus infinity. At this levels small increases in earnings and, therefore, consumption lead to a large gain in terms of utility. Despite introducing a monetary cost, as long as there are not borrowing constraints, the gain remains very large. This is why at the low end of the human capital distribution migration should always be expected to be high.

Table 8: Mexican Immigrants in the US Before and After the Restrictive Program

\begin{tabular}{|l|r|r|r|r|r|r|r|r|r|}
\hline & \multicolumn{4}{|c|}{ Before the Program } & \multicolumn{4}{c|}{ After the Program } & \\
\hline & Stayers & Imm. & Rate & Perc. & Stayers & Imm. & Rate & Perc. & Change \\
\hline No School & 1652 & 651 & 28.27 & 21.19 & 1694 & 569 & 25.14 & 22.35 & -12.65 \\
Elementary & 12092 & 1180 & 8.89 & 38.41 & 12054 & 981 & 7.52 & 38.53 & -16.93 \\
Low Sec. & 8780 & 531 & 5.70 & 17.27 & 8734 & 411 & 4.49 & 16.14 & -22.59 \\
High School & 3946 & 711 & 15.27 & 23.14 & 3989 & 585 & 12.79 & 22.98 & -17.75 \\
Total & 26470 & 3073 & 10.40 & 100.00 & 26470 & 2545 & 8.77 & 100.00 & -2.00 \\
\hline
\end{tabular}

Overall, such a policy is capable of effectively controlling the flow of immigrants, but it has a negative effect in terms of controlling the quality of this flow. More restrictions on immigration results in lower skilled immigrants, having a larger share of the total pool, which lowers the average human capital imported into the US and widens its distribution among immigrants. This is shown in figure 5 .

We saw above that with the Progresa program, emigration decreases because of the effect that the program has on the educational distribution of the Mexican population. In this case the effect on migration is an indirect one. The restrictive policy instead, has a direct effect on migration by reducing its expected gain. However it has also an indirect effect on the human capital distribution of the Mexican population both in the short and long run. In the short run the effect is due to the different pattern of emigration. The worsening of the educational distribution of immigrants implies that stayers are now better educated than before the policy. However, while the effect on the immigrant distribution is significant, the effect on the whole Mexican population is diluted because of the higher number of stayers.

In the long run, the reduction of the return to migration may have an effect on the educational choices of parents for their children. Figure 6 shows that in the long run the distribution of stayers does not change significantly. The short run effect that tends to compress the educational distribution is compensated by the educational choices. In fact, the policy decreases the incentive 
Figure 5: Educational Distribution of Immigrants in the US Before and After the Restrictive Policy

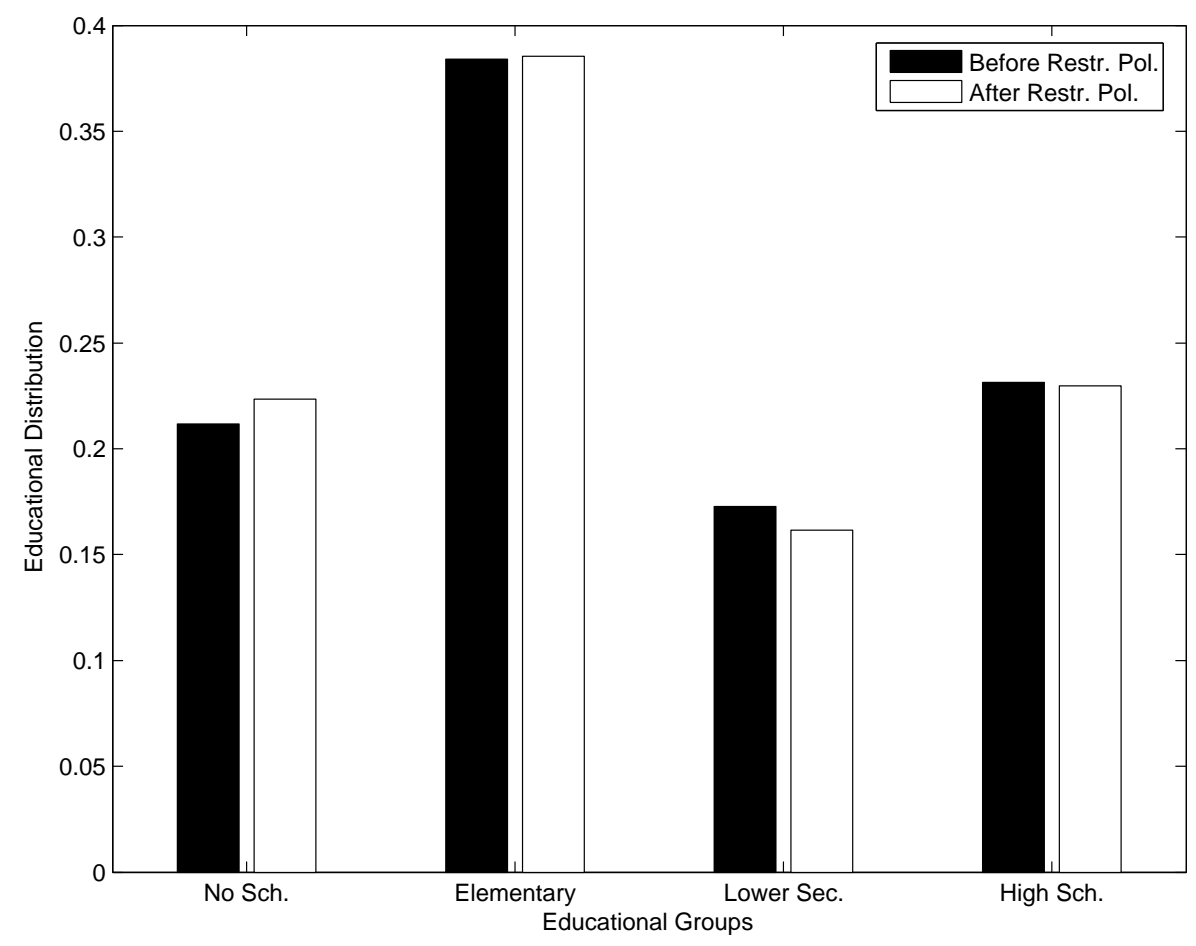

to migrate especially of middle educated. Therefore, after the policy, parents find more attractive to push their children at both ends of the distribution.

The fact that in the long run the educational distribution in Mexico does not change has an important policy implication for the destination country. Although the restrictive policy is effective, it needs to be continuously implemented by the destination country to sustain the effect.

\section{Conclusion}

Mexico offers an unique opportunity for researchers to understand the causes of emigration, because the vast majority of Mexican migrants choose the US as their country of destination. This allows their performance in the labor market to be observed and compared with individuals remaining in Mexico. Analyzing data from both the US and Mexican Censuses, an U-shaped relationship between education and migration emerges: the lowest educated and the highest 
Figure 6: Educational Distribution of Stayers in Mexico Before and After the Restrictive Policy

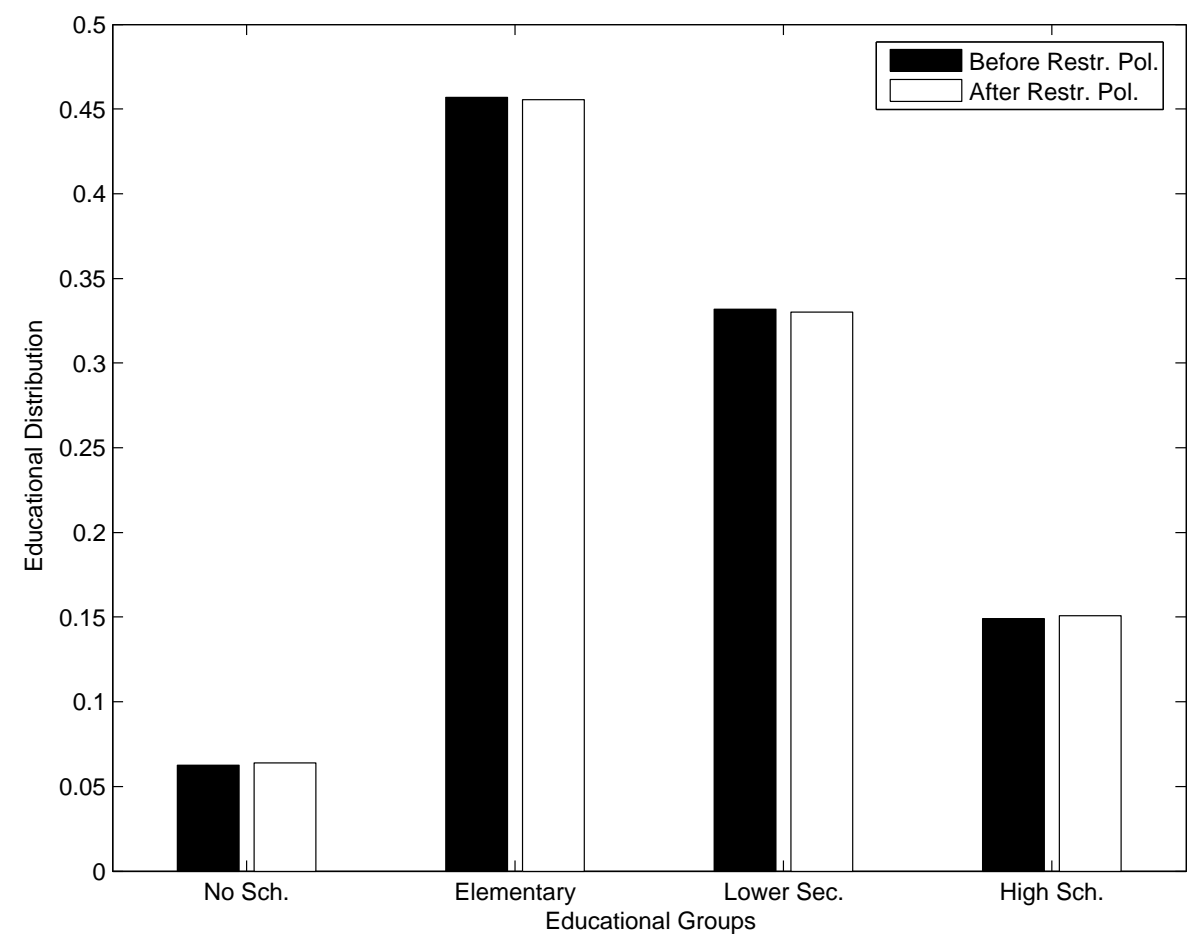

educated Mexicans are those who have the most to gain from migrating to the US. Conversely, the middle educated, i.e. those Mexicans with six and nine years of schooling, have relatively lower gains and, therefore, tend to migrate less. The model I propose reproduces both qualitatively and quantitatively this main pattern.

Using the model I evaluate two types of policies that can affect education and migration. Given the shape of the education-migration relationship, the model seeks to predict the effect of different policies on both the migration flow and the educational distribution of immigrants and non-migrants. The first type of policy I consider in this paper is implemented in the source country, and only indirectly affects migration: the Progresa program of the Mexican government. The second is a hypothetical restrictive immigration policy implemented by the US - the destination country - to reduce the immigration inflow.

With regards to the first policy, I show that this program is effective not only in improving the educational distribution of Mexicans, but also in lowering the emigration pressure that is mainly directed at the United States. Moreover, I find that the quality of immigrants in the US 
will improve substantially as a result of the program. Restrictive immigration policies, instead, may have undesirable effects. They are effective in reducing the emigration rates from source countries. However, my findings demonstrate that the disincentive to migrate introduced by these policies is stronger for higher educated potential migrants than for those at the lower end of the educational distribution. This impacts negatively on the quality of immigrants and results in a significant loss of human capital imported by the US. Moreover, since such restrictive policies have no effect on the educational distribution in Mexico in the long run the pressure at the border is not altered. In fact at lower levels of education immigrants are generally very poor and are not easily discouraged from the prospect of making a better living elsewhere. The everyday experience of thousands of Mexicans crossing the border illegally, often at great risk to their lives to find a low paid job in the US, is testimony to this. My analysis of the Progresa program suggests that this phenomenon can be mitigated more effectively by increasing education opportunities in source countries, rather than by policies implemented in the destination country that aim to discourage migration.

My explanation in terms of intergenerational altruism and transmission of human capital has also another important implication. Contrary to previous findings (Borjas (1993)), my model, implies that future generations of recent immigrants from Mexico should be expected to fast assimilate. This is because selection at higher levels of human capital is positive and immigrants transmit more human capital to their children than that used by the labor market. Thus, second generation immigrants are expected to perform better than first generation immigrants, overcoming the disadvantage their parents faced in relation to the native population.

\section{References}

Angelucci, M. (2004): "Aid and Migration: An Analysis of the Impact of Progresa on the Timing and Size of Labour Migration," IZA - Institute for the Study of Labor, Bonn, Germany, (Discussion Paper 1187).

Behrman, J. P. S., And P. Todd (2001): "Progressing through Progresa: An Impact Assessment of a School Subsidy Experiment," University of Pennsylvania and the International Food Policy Research Institute, Washington, D.C. 
BorJas, G. J. (1987): "Self Selection and the Earnings of Immigrants," American Economic Review, 77(4), 531-553.

(1991): "Immigration and Self Selection," in Immigration, Trade and the Labor Market, ed. by J. Abowd, and R. Freeman. University of Chicago Press, Chicago.

(1993): "The Intergenerational Mobility of Immigrants," Journal of Labor Economics, 11(1), 113-135.

- (1995): "Assimilation and Changes in Cohort Quality Revisited: What Happened to Immigrant Earnings in the 1980s?," Journal of Labor Economics, 13(2), 201-245.

- (1996): "The Earnings of Mexican Immigrants in the United States," Journal of Development Economics, 51, 69-98.

(1999): "The Economic Analysis of Immigration," in Handbook of Labor Economics, ed. by O. C. Ashenfelter, and D. Card. North Holland, Amsterdam.

- (2000): "The Economic Progress of Immigrants," in Issues in the Economics of Immigration, ed. by G. J. Borjas. University of Chicago Press, Chicago.

CARD, D. (2004): "Is the New Immigration Really So Bad?," IZA - Institute for the Study of Labor, Bonn, Germany, (Discussion Paper N.1119).

Chiquiar, D., and G. H. Hanson (2005): "International Migration, Self Selection, and the Distribution of Wages: Evidence from Mexico and United States," Journal of Political Economy, 113(2), 239-281.

Costanzo, Joe, C. D. C. I. D. G., and R. Ramirez (2001): "Evaluating Components of International Migration: The Residual Foreign Born Population," U.S. Bureau of the Census, Division Working Paper, $(61)$.

De la Croix, D., And M. Doepke (2003): "Inequality and Growth: Why Differential Fertility Matters," American Economic Review, 93(4), 1091-1113.

Duleep, H., And M. Regets (2002): "The Elusive Concept of Immigrant Quality: Evidence from 1970-1990," IZA - Institute for the Study of Labor, Bonn, Germany Discussion Paper, (631). 
Gourieroux, C., And A. Monfort (1996): Simulation-Based Econometric Methods. Oxford University Press, Oxford, UK.

Hanson, G. H., And A. Spilimbergo (1999): "Illegal Immigration, Border Enforcement, and Relative Wages: Evidence from Apprehensions at the U.S.-Mexican Border," American Economic Review, (89), 1337-1357.

Hendricks, L. (2001): "The Economic Performance of Immigrants: a Theory of Assortative Matching," International Economic Review, 42(2), 417-449.

- (2002): "How Important is Human Capital for Development? Evidence from Immigrant Earnings," American Economic Review, 92(1), 198-219.

Laibson, D., A. Repetto, and J. Tobacman (2005): "Estimating Discount Functions with Consumption Choices over the Lifecycle," Mimeo Harvard.

Lalonde, R. J., And R. H. Topel (1991): "Immigrants in the American Labor Market: Quality, Assimilation, and Distributional Effects.," American Economic, 81(2), 297-302.

McFadden, D. (1989): "A Method of Simulated Moments for Estimation of Discrete Response Models without Numerical Integration," Econometrica, 57(5), 995-1026.

Schultz, T. P. (2004): "School Subsidies for the Poor: Evaluating the Mexican Progresa Poverty Program," Journal of Development Economics, 74(1), 199-250.

Trejo, S. J. (2001): "Intergenerational Progress of Mexican-Origin Workers in the US Labor Market," IZA - Institute for the Study of Labor, Bonn, Germany, (Discussion Paper N.377).

Urrutia, C. (1998): "On the Self Selection of Immigrants," mimeo, Universidad Carlos III de Madrid, Madrid, Spain. 


\section{Appendix A}

Table A.1: Mexican Immigrants in the US compared with Mexican stayers (18 to 30 years old)

\begin{tabular}{|l|r|r|r|r|r|r|}
\hline & \multicolumn{2}{|c|}{ All } & \multicolumn{2}{c|}{ Men } & \multicolumn{2}{c|}{ Women } \\
\hline & Stayers & Imm. & Stayers & Imm. & Stayers & Imm. \\
\hline No School & 6.98 & 12.27 & 1.84 & 7.49 & 2.13 & 7.14 \\
Low Ed. & 17.57 & 7.82 & 10.17 & 4.04 & 10.26 & 3.36 \\
Primary & 24.39 & 23.22 & 22.95 & 21.38 & 25.39 & 20.81 \\
Low Sec. & 29.01 & 24.00 & 43.71 & 30.66 & 38.32 & 29.08 \\
High Sch. & 13.95 & 21.93 & 15.27 & 28.24 & 17.42 & 29.09 \\
College & 8.10 & 10.75 & 6.06 & 8.19 & 6.48 & 10.52 \\
\hline
\end{tabular}

Table A.2: Mexican Immigrants in the US compared with Mexican stayers (31 to 45 years old)

\begin{tabular}{|l|r|r|r|r|r|r|}
\hline & \multicolumn{2}{|c|}{ All } & \multicolumn{2}{c|}{ Men } & \multicolumn{2}{c|}{ Women } \\
\hline & Stayers & Imm. & Stayers & Imm. & Stayers & Imm. \\
\hline No School & 6.98 & 12.27 & 4.73 & 10.74 & 7.32 & 11.37 \\
Low Ed. & 17.57 & 7.82 & 15.74 & 6.98 & 18.12 & 7.25 \\
Primary & 24.39 & 23.22 & 22.64 & 23.18 & 26.16 & 24.26 \\
Low Sec. & 29.01 & 24.00 & 28.04 & 23.90 & 24.43 & 23.79 \\
High Sch. & 13.95 & 21.93 & 15.19 & 21.98 & 15.15 & 21.00 \\
College & 8.10 & 10.75 & 13.65 & 13.21 & 8.81 & 12.34 \\
\hline
\end{tabular}

Table A.3: Mexican Immigrants in the US compared with Mexican stayers (over 45 years)

\begin{tabular}{|l|r|r|r|r|r|r|}
\hline & \multicolumn{2}{|c|}{ All } & \multicolumn{2}{c|}{ Men } & \multicolumn{2}{c|}{ Women } \\
\hline & Stayers & Imm. & Stayers & Imm. & Stayers & Imm. \\
\hline No School & 6.98 & 12.27 & 4.73 & 10.74 & 7.32 & 11.37 \\
Low Ed. & 17.57 & 7.82 & 15.74 & 6.98 & 18.12 & 7.25 \\
Primary & 24.39 & 23.22 & 22.64 & 23.18 & 26.16 & 24.26 \\
Low Sec. & 29.01 & 24.00 & 28.04 & 23.90 & 24.43 & 23.79 \\
High Sch. & 13.95 & 21.93 & 15.19 & 21.98 & 15.15 & 21.00 \\
College & 8.10 & 10.75 & 13.65 & 13.21 & 8.81 & 12.34 \\
\hline
\end{tabular}

Table A.4: Return to Education Regression for the US

\begin{tabular}{|l|r|r|}
\hline & Coeff. & Std. Err. \\
\hline Intercept & 0.6778 & 0.0073 \\
Yrs of School & 0.1063 & 0.0005 \\
Experience & 0.0414 & 0.0003 \\
Experience $^{2} / 100$ & -0.0636 & 0.0006 \\
\hline N. of Obs & 447144 & \\
R. Sq & 0.1618 & \\
\hline
\end{tabular}

